\title{
$\mathrm{Cu}_{3} \mathrm{Si}$ 负极脱/嵌锂过程的赝电容行为与二级相变的关联性
}

\author{
史傲迪陈思郑淞生* 王兆林* \\ (厦门大学能源学院 福建厦门 361102)
}

\begin{abstract}
摘要 高能量密度的锂离子电池的应用日趋广泛, 寻找兼具高能量密度、快速充放电、长循环寿命能力的材料成为了 研究热点. 采用冶金法制备了纯度较高的 $\mathrm{Cu}_{3} \mathrm{Si}$ 相, 扣式半电池测试表明, $\mathrm{Cu}_{3} \mathrm{Si}$ 负极在 $0.1 \mathrm{C}$ 倍率下首圈放电比容量 759 $\mathrm{mAh} \cdot \mathrm{g}^{-1}$, 首圈库伦效率 $96.56 \%$, 循环 200 圈之后放电比容量是 $822 \mathrm{mAh} \cdot \mathrm{g}^{-1}$, 容量保持率达到 $98 \%$. 且其充放电曲线 为斜坡状，具有赝电容特性. 首次发现了 $\mathrm{Cu}_{3} \mathrm{Si}$ 材料兼具电池和电容属性，二者共同储存了电荷，且以电容贡献率为主. 经嵌锂后的 $\mathrm{Cu}_{3} \mathrm{Si}$ 样品的差示扫描量热法(DSC)曲线在 550 600 ${ }^{\circ} \mathrm{C}$ 有一个明显台阶, 对应于比热容的变化, 且充放电

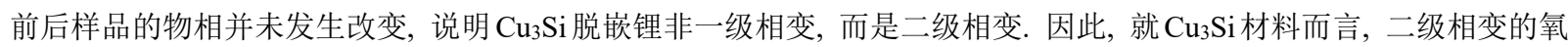
化还原过程在电化学特性上表现为赝电容行为.
\end{abstract}

关键词 冶金法; $\mathrm{Cu}_{3} \mathrm{Si}$; 电化学特性; 赝电容; 二级相变

\section{Correlation between the Pseudo-Capacitance Behavior and the Second-Order Phase Transition in the $\mathrm{Li}^{+}$ Insertion/Desertion in $\mathrm{Cu}_{3} \mathrm{Si}$

\author{
Aodi Shi Si Chen Songsheng Zheng* Zhaolin Wang*
} \\ (College of Energy, Xiamen University, Xiamen, Fujian 361102)}

\begin{abstract}
Lithium-ion batteries with high energy density have urgent demand, especially in the fields of pure electric vehicles, smart phones, laptops, wind power generation and energy storage. Therefore, more and more attention has been paid on materials with high energy density, rapid charge/discharge capability and long cycle life. In this paper, pure $\mathrm{Cu}_{3} \mathrm{Si}$ phase was prepared by metallurgical process, and the electrochemical characteristics of the as prepared $\mathrm{Cu}_{3} \mathrm{Si}$ samples were studied by using CR2025 button half-cell structure with metal lithium sheet as reference electrode and Celgard 2500 as diaphragm. The results showed that, at a current density of $0.1 \mathrm{C}\left(420 \mathrm{~mA} \cdot \mathrm{g}^{-1}\right)$, it possessed a first-cycle discharge specific capacity of 759 $\mathrm{mAh} \cdot \mathrm{g}^{-1}$ with a coulomb efficiency of $96.56 \%$. It remained $822 \mathrm{mAh} \cdot \mathrm{g}^{-1}$ after 200 cycles with a capacity retention rate of $98 \%$. It retained $776,700,580,500,440$ and $405 \mathrm{mAh} \cdot \mathrm{g}^{-1}$ at a testing rate of $0.1 \mathrm{C}, 0.2 \mathrm{C}, 0.4 \mathrm{C}, 0.6 \mathrm{C}, 0.8 \mathrm{C}$ and $1 \mathrm{C}$, respectively. The specific capacity was stabilized at around $790 \mathrm{mAh} \bullet \mathrm{g}^{-1}$ when the current density was restored to $0.1 \mathrm{C}$, which did not decrease significantly compared with the initial value. Moreover, the impedance was about $60 \Omega$, lower than that of the reported Si@C anode. Thus, it suggested that introducing $\mathrm{Cu}$ would greatly reduce the charge transfer resistance. It was worth noting that the charge/discharge curve was slope like and had pseudo capacitance characteristics. Furthermore, the cyclic voltammetry $(\mathrm{CV})$ measurement was carried out at scanning rates of $0.1,0.2,0.4,0.6,0.8$ and $1.0 \mathrm{mV} / \mathrm{s}$, respectively. The results discovered for the first time that the as-prepared $\mathrm{Cu}_{3} \mathrm{Si}$ possessed the characteristic of both battery and capacitance. They together stored the charges, and the capacitance dominated the contribution. Moreover, an clear step could be observed at $550-600{ }^{\circ} \mathrm{C}$ in the differential scanning calorimetry (DSC) curve of the as-prepared $\mathrm{Cu}_{3} \mathrm{Si}$ sample after discharged, relating to a change in the specific heat capacity. Moreover, the sample phase did not change before and after the charge/discharge process. Therefore, it was determined that the $\mathrm{Li}^{+}$insertion/desertion process of $\mathrm{Cu}_{3} \mathrm{Si}$ was not a first-order phase transition but a second-order phase transition process. To be concluded, for $\mathrm{Cu}_{3} \mathrm{Si}$ anode materials, the redox process was a second-order phase transition, which exhibited a pseudo capacitive behavior in its electrochemical properties.

Keywords metallurgical method; $\mathrm{Cu}_{3} \mathrm{Si}$; electrochemical characteristics; pseudo-capacitance; second order phase transition
\end{abstract}

\footnotetext{
*E-mail: Songsheng@xmu.edu.cn; ForestWang@xmu.edu.cn

Received August 4, 2021; published October 8, 2021.

Project supported by the National Natural Science Foundation of China (No. 21875199), the National "Double First-class" Construction Special Funds Project (No. 0290-X2100502), the Xiamen University College of Energy-Weifang Senokate Broad Spectrum Hydrogen Fuel Cell R\&D Center Project (No. XDHT2020024C), the Xiamen University College of Energy-Zibo High-tech Industrial Development Zone Hydrogen Energy R\&D Center (No. XDHT2020023C), and the Commissioned Development Project of Energy Research Institute of Hefei Comprehensive National Science Center (No. XDHT2020305A).

国家自然科学基金面上项目(No. 21875199)、双一流建设重点高校项目(No. 0290-X2100502)、廈门大学能源学院一潍坊赛诺凯特广谱型氢能燃料电池 研发中心项目(No. XDHT2020024C)、厦门大学能源学院一淄博高新技术产业开发区氢能研发中心(No. XDHT2020023C)和合肥综合性国家科学中心 能源研究院委托开发项目(No. XDHT2020305A)资助项目.
} 


\section{1 引言}

高能量密度的锂离子电池的需求与应用日趋广泛, 特别是在纯电动汽车、智能手机、笔记本电脑、风力发 电储能等领域的需求呈现快速增长 ${ }^{[1-2]}$. 但现有的商用 锂离子电池无法满足市场对大容量、快速充放电的需求, 因此, 近年来高性能高比容量的锂离子电池始终是一个 研究的热点 ${ }^{[3-4]}$.

锂离子电池是一种发生法拉第过程的电化学储能 装置, 即通过氧化还原反应在电极材料内部储存锂离 子, 能量密度高, 但是因为反应受到锂离子在固相中扩 散的限制, 导致充放电速度慢 ${ }^{[5-8]}$. 另一种电化学储能装 置是双电层超级电容器(Electric double layer capacitor, EDLC), 即通过双电层静电吸附在材料表面存储能量, 这个过程不涉及氧化还原反应 ${ }^{[9-10]}$. 电容储能只发生在 电极表面, 所以受到表面扩散控制, 而通常情况下表面 扩散速率远高于固态扩散, 因此 EDLC 具有快速充放电 能力强、循环寿命长等优点 ${ }^{[11-15]}$. 但其能量密度比锂离 子电池低, 并且材料成本(例如石墨烯)通常比电池材料 高 ${ }^{[16-20]}$. 因此, 寻找兼具两者优点的材料具有重要的理 论意义和研究价值.

近年来, 研究人员发现有些材料同时具备电池和电 容的特性. 如: Okubo 等 ${ }^{[21]}$ 的研究发现当钴酸锂颗粒不 断缩小时, 在电化学极化曲线(Cyclic polarization, CP)测 试中的充放电平台越来越不明显, 且当颗粒尺寸达到 6 $\mathrm{nm}$ 时, 其充放电平台彻底消失. 电池和电容虽然是两 种截然不同的电化学储能装置, 但随着材料种类的增 多、纳米结构技术的发展, 人们发现了更多处于 “Battery” 和 “EDLC” 中间地带的材料, 这类材料模糊 了电池和电容的界限 ${ }^{[22]}$. 一般把这类材料称为赝电容 材料 ${ }^{[23]}$, 这类材料同时具备电池的高能量密度和超级 电容器的快速充放电、长循环寿命能力.

赝电容材料的可逆电化学过程分为氧化还原反应、 嵌入/脱出机制、欠电势沉积 ${ }^{[24-25]}$, 对于赝电容材料一般 通过电化学测试进行表征分析. 赝电容材料充放电时发 生法拉第过程, 必定有物质的氧化还原, 目前, 在这方 面的研究报道较少.

本工作用冶金法制备了 $\mathrm{Cu}_{3} \mathrm{Si}$ 金属间化合物, 且电 化学测试结果表明该材料具有赝电容特性, 本工作进一 步计算了电容和电池行为对于储存电荷的贡献, 并深入 讨论了其相变过程.

\section{2 结果与讨论}

\section{1 物理表征}

如图 1(a)所示, 本工作采用高纯度 $\mathrm{Cu}$ 颗粒和 $\mathrm{Si}$ 颗 粒, 采用冶金法熔炼得到 $\mathrm{Cu}_{3} \mathrm{Si}$ 锭. 图 1(a) 原材料分别 是长度 $0.5 \mathrm{~cm}$ 的柱状高纯铜颗粒和尺寸 $1 \mathrm{~cm}$ 的不规则 块状工业高纯硅. 通过冶金法制备的样品呈圆台状, 最
大直径 $44.60 \mathrm{~mm}$, 最大高度 $32.07 \mathrm{~mm}$. 样品上表面呈 银黑色, 形状平整, 分布着细小孔洞. 样品侧面呈银白 色, 金属光泽明显, 有凹陷的小坑.

进一步对所制备样品进行 XRD 表征, 如图 1(b)所 示, 其特征峰与 PDF 标准卡片 $\mathrm{Cu}_{3} \mathrm{Si}$ PDF\#51-0916 吻合 得很好 ${ }^{[26]}$, 且在 $2 \theta$ 为 $44.5^{\circ}$ 和 $44.9^{\circ}$ 处有两个明显的衍射 峰, 分别对应于 $\mathrm{Cu}_{3} \mathrm{Si}$ 相(012)、(300)晶面. $\mathrm{Cu}_{3} \mathrm{Si}$ 相的主 要衍射峰强度高、形状尖锐, 说明样品中 $\mathrm{Cu}_{3} \mathrm{Si}$ 相的结 晶度好.

另一方面, 从图 1(b)中 $\mathrm{Cu}$ 和 $\mathrm{Si}$ 原料颗粒样品的 XRD 衍射图谱, 以及与之相对应的 PDF 标准卡片 $\mathrm{Cu}$ PDF\#04-0836、Si PDF\#99-0092 对比可以看出 ${ }^{[27-28]}$, 样 品中并未观察到明显的 $\mathrm{Cu}$ 和 $\mathrm{Si}$ 单质的衍射峰, 也未出 现 $\mathrm{Cu}$ 和 $\mathrm{Si}$ 的氧化物特征峰. 说明样品并未发生明显的 氧化, 因此, 熔炼过程采用石墨坩埚加盖可有效防止因 熔体氧化而改变原有的化学配比. 样品的 XRD 图谱中 含有一些微弱的杂相峰, 其相对强度远小于 $\mathrm{Cu}_{3} \mathrm{Si}$ 物相 衍射峰强度，由此表明本工作采用冶金法成功制备出纯 度较高的 $\mathrm{Cu}_{3} \mathrm{Si}$ 相.

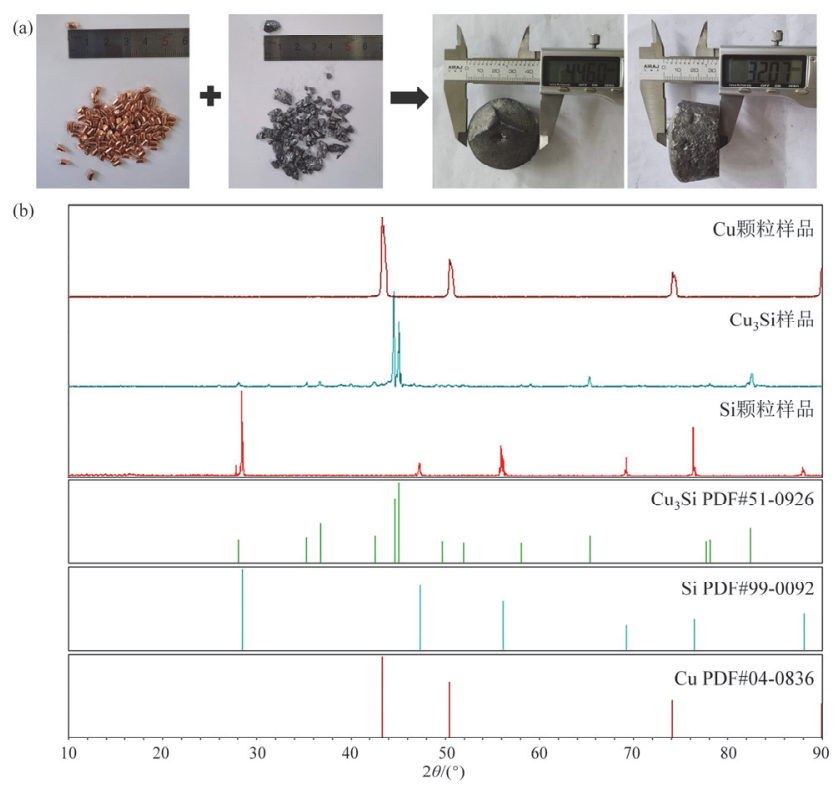

图 1 (a)样品实物图; (b) XRD 图

Figure 1 (a) Samples physical images; (b) XRD patterns

为了明确所制备的样品中的杂相, 我们进一步对样 品进行扫描电镜和能量色散 $\mathrm{X}$ 射线光谱(EDS)分析, 结 果如图 2 所示.

图 2(a)为所制备样品的坚直中切面, 切面呈银白色, 分布着一些细小孔洞. 这可能是由于 $\mathrm{Cu}-\mathrm{Si}$ 两相体系存 在共晶凝固过程，而此凝固过程伴随着体积收缩，从而 导致出现均匀分布的小孔洞结构.

进一步将所制备样品的坚直中切面通过金相抛光 后进行扫描电镜检测，如图 2(b)所示，可观察到主相明 显占样品的绝大多数, 而均布于周围的第二相经放大后 
如图 2(c)所示, 第二相主要呈针棒状特征, 其宽度约为 $5 \mu \mathrm{m}$. 对所制备样品的两种不同的物相进行 EDS 能谱 扫描, 图 2(d)和(e)分别为主相和第二相的 EDS 检测取点 示意图, 而图 2(f)则为 EDS 的扫描结果, 从结果得知, 样品主相中的 $\mathrm{Cu}$ 原子百分含量为 $49.92 \%, \mathrm{Si}$ 为 $17.41 \%$, $n(\mathrm{Cu}): n(\mathrm{Si})=2.87$, 非常接近 3 , 表明主相为 $\mathrm{Cu}_{3} \mathrm{Si}$, 这 与 XRD 的检测结果相一致. 而第二相中 $\mathrm{Cu}$ 的原子百分 含量仅为 $0.68 \%, \mathrm{Si}$ 则占 $80.24 \%$, 说明第二相为 $\mathrm{Si}$ 相, 但图 1 (b)的 XRD 测试结果中并没有出现明显的 $\mathrm{Si}$ 衍射 峰, 说明第二相 $\mathrm{Si}$ 相在样品中的占比很小, 从 XRD 的 检测极限推测, $\mathrm{Si}$ 相的比例应小于 $1 \%$. 由此可进一步确 认, 本文成功制备出纯度较高的 $\mathrm{Cu}_{3} \mathrm{Si}$ 样品. 而从 EDS 的检测图谱中均检测出相当量的碳含量, 可能是由于本 研究中采用了石墨坩埚和石墨模具造成的样品污染.

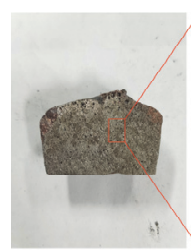

(a)

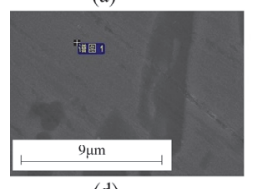

(d)

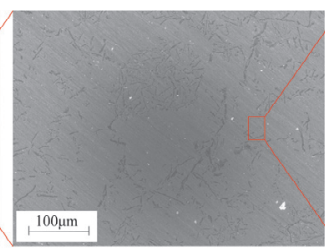

(b)

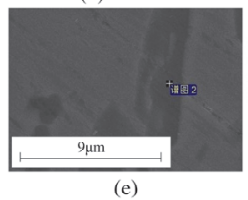

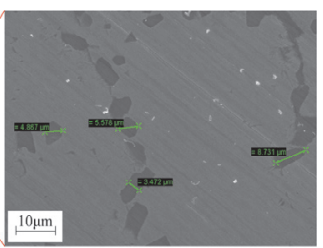

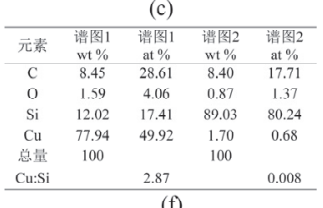

(f)
图 2 (a)样品截面; (b), (c) SEM 图; (d), (e), (f) EDS 能谱

Figure 2 (a) Sample cross-section; (b), (c) SEM images; (d), (e), (f) EDS spectra
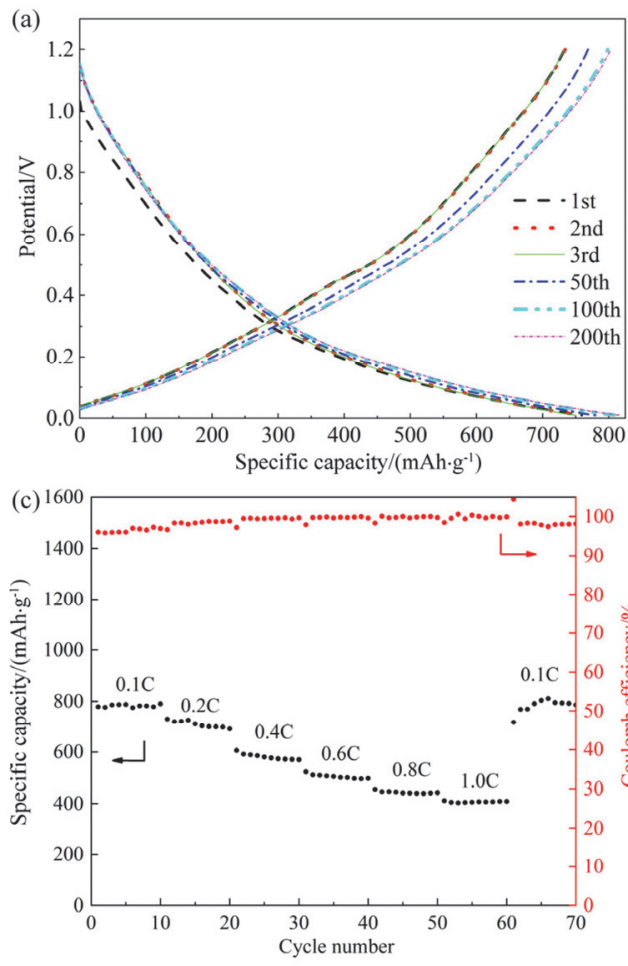

\section{2 电化学表征}

本工作以金属锂片为参比电极, Celgard 2500 为隔 膜, 采用 $\mathrm{CR} 2025$ 扣式半电池结构研究了 $\mathrm{Cu}_{3} \mathrm{Si}$ 样品的 电化学特性, 其充放电特性如图 3 所示.

图 3(a) 是样品在 $0.1 \mathrm{C}$ 倍率下的充放电曲线, 从图中 可以看出：第 $1 、 2 、 3$ 次的充放电曲线完全重合，第 50 、 100、200 次的充放电曲线与第 3 次相差很小、曲线非常 相似. 值得注意的是, 所制备样品的充放电曲线为斜坡 状，并没有观测到常规负极材料所应有的充放电平台. 电量随着电位的增加几乎呈线性增加, 恒电流充电和放 电曲线的具有近似线性的斜率, 由此可以看出, 充放电 曲线表现为电容特性.

图 3(b) 是样品在 $0.1 \mathrm{C}$ 倍率下的循环性能图, 可以看 出所制备的样品表现出非常稳定的充放电性能. 首次放 电比容量 $759 \mathrm{mAh} \cdot \mathrm{g}^{-1}$, 首次库伦效率 $96.56 \%$. 样品的 最高放电比容量为 $837 \mathrm{mAh} \cdot \mathrm{g}^{-1}$, 循环 200 次之后放电 比容量是 $822 \mathrm{mAh} \cdot \mathrm{g}^{-1}$, 容量保持率达到 $98 \%$, 且从第 五次开始库伦效率一直保持在 $98 \%$ 以上.

图 3(c)是样品的倍率性能图, 从图中可以看出, 样 品的首次放电比容量 $776 \mathrm{mAh} \cdot \mathrm{g}^{-1}$, 首次库伦效率 $96 \%$. 在倍率为 $0.1 \mathrm{C} 、 0.2 \mathrm{C} 、 0.4 \mathrm{C} 、 0.6 \mathrm{C} 、 0.8 \mathrm{C}$ 和 $1 \mathrm{C}$ 时, 比 容量分别达到 776、700、580、500、440 和 $405 \mathrm{mAh}$ • $\mathrm{g}^{-1}$. 当倍率回到 $0.1 \mathrm{C}$ 时, 比容量回到 $790 \mathrm{mAh} \cdot \mathrm{g}^{-1}$. 由 此说明, 样品在倍率性能测试循环后, 其 $0.1 \mathrm{C}$ 的充放电 比容量与初始比较, 并未发生明显的降低.

图 3(d)则是样品的交流阻抗图, 高频区半圆直径大
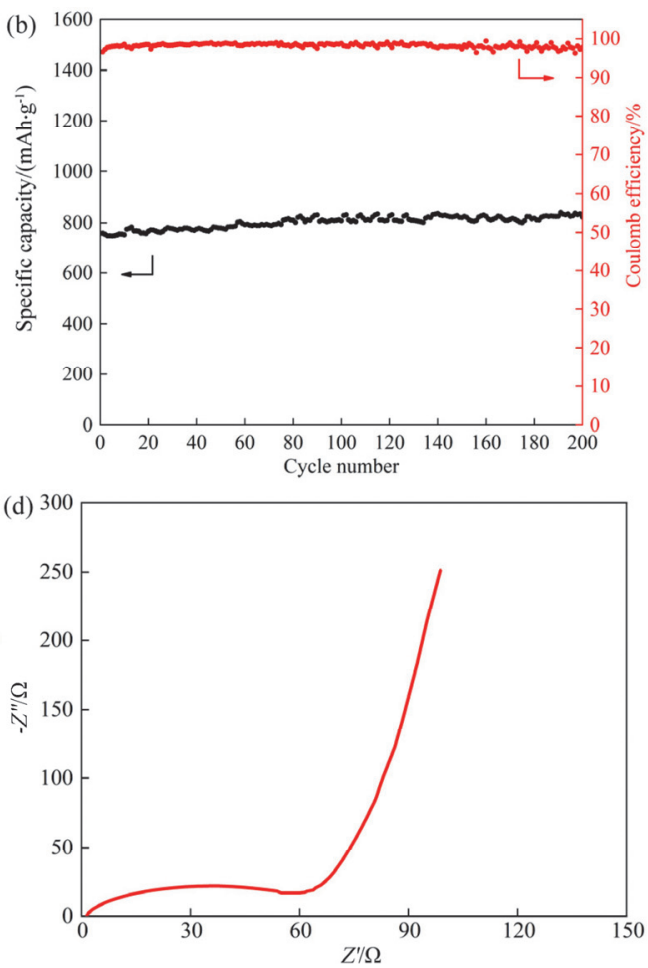

图 3 (a)充放电曲线; (b)循环性能图; (c)倍率性能图; (d) 交流阻抗图

Figure 3 (a) Charge-discharge curve; (b) cycling performance; (c) rate capability; (d) EIS diagram 
小表示的是电极界面处的电荷传输阻抗, 半圆直径越 小, 电荷转移电阻越小. 从图中可以明显得出其半圆直 径约为 $60 \Omega$, 明显小于已报道的 $\mathrm{Si} @ \mathrm{C}$ 负极的电化学交 流阻抗值 ${ }^{[29-31]}$. 说明本工作所制备的 $\mathrm{Cu}_{3} \mathrm{Si}$ 负极, 由于 $\mathrm{Cu}$ 的加入极大降低了负极材料的电荷转移阻力.

一般来说, 电池材料嵌入脱出锂离子时会发生氧化 还原反应, 在恒电流充放电曲线中会有平台. 而有一些 电池材料的电化学行为却类似于电容, 但又不是电容, 因此一般称这些材料为 “噟电容”。傅强等 ${ }^{[32]}$ 研究了 $\mathrm{Ca}_{1.5} \mathrm{~V}_{2}\left(\mathrm{PO}_{4}\right)_{3}$ 材料, 其充放电曲线具有电容特性, 在 $\mathrm{CV}$ 图中没有观察到氧化还原峰，是一种赝电容材料.

对于赝电容材料, 可以使用 $\mathrm{CV}$ 测试进一步表征. 通过将扫描速率 $(v, \mathrm{mV} / \mathrm{s})$ 与所得电流响应 $(i, \mathrm{~A})$ 进行对 应, 能够分辨出当前电化学过程是扩散控制还是表面控 制. 对于由半无限线性扩散限制的氧化还原反应, 电流 $i$ 随 $v^{1 / 2}$ 变化, 则为电池行为; 如果电流 $i$ 随 $v$ 呈线性变 化, 说明反应为表面控制过程, 则是一种电容行为.

基于 $\mathrm{CV}$ 测试, 其响应电流与扫描速率之间的关系 如公式(1)所示 ${ }^{[33-35]}$ :

$$
i=a v^{b}
$$

式中 $a, b$ 是常数. 对两边取对数可得公式(2):

$$
\lg i=\lg a+b \lg v
$$

根据公式(2), 作扫描速率与响应对流的对数曲线 图, 并通过拟合得到 $b$ 的数值. 比如, $\mathrm{LiFePO}_{4}$ 和 $\mathrm{Nb}_{2} \mathrm{O}_{5}$ 都是依靠锂离子嵌入脱出进行储能, 前者 $b$ 值为 0.5 , 表 现为电池属性, 后者 $b$ 值为 1.0 , 则表现为噟电容属 性 ${ }^{[36]}$.

本工作分别采用扫描速率为 $0.1 、 0.2 、 0.4 、 0.6 、 0.8$ 和 $1.0 \mathrm{mV} / \mathrm{s}$ 对所制备的样品进行 CV 测试, 其结果如图 4 所示.

从图 4(a)中可以看出, 样品的 $\mathrm{CV}$ 曲线仍然存在明 显的氧化还原峰, 说明 $\mathrm{Cu}_{3} \mathrm{Si}$ 并不是简单的电容特性, 且峰值电流随着扫描速率增加而渐渐变大, 氧化还原峰

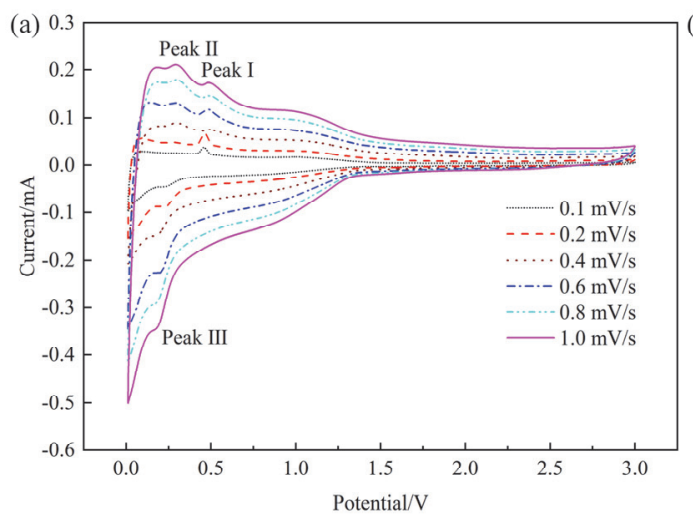

变得愈加明显. 进一步对三个不同的氧化还原峰值作 $\lg i$ 对 $\lg v$ 的对数关系图如图 4(b)所示, 通过拟合求得图 4(a)中电流峰值 Peak I、Peak II 和 Peak III 所对应的斜率 值 $b$ 分别为 $0.62736 、 0.91953$ 和 0.86899 , 处于 $0.5 \sim 1$ 之间, 表明所制备的样品的电化学特性是既有电池属 性，又包含电容属性成分.

为了明晰所制备的样品的电池和电容属性的贡献 率大小，本工作采用公式(3)计算出特定扫描速率下的

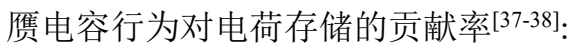

$$
i=k_{1} v+k_{2} v^{1 / 2}
$$

上式中 $k_{1}$ 和 $k_{2}$ 分别表示电容和电池属性在 $\mathrm{CV}$ 测试中的 贡献率. 而 $k_{1} v$ 表示噟电容行为, $k_{2} v^{1 / 2}$ 表示电池行为.

本工作根据不同扫描速率的 $\mathrm{CV}$ 曲线, 对电容贡献 率进行了拟合计算, 结果如图 5 所示.

图 5(a)到(f)分别是扫描速率为 $0.1 、 0.2 、 0.4 、 0.6$ 、 0.8 和 $1.0 \mathrm{mV} / \mathrm{s}$ 时的 $\mathrm{CV}$ 曲线中赝电容所占的比例(阴影 部分的面积)或者贡献率. 首先, 我们将许多的特定电 压 $(V, \mathrm{mV})$ 与 $k_{1} v(i, \mathrm{~mA})$ 通过平滑曲线连接起来, 进行非 线性拟合; 其次，对拟合的闭合曲线进行积分求面积; 接着, 对特定扫描速率下的 $\mathrm{CV}$ 曲线进行积分求面积. 最后, 将拟合曲线的面积除以 $\mathrm{CV}$ 曲线面积所得的值即 为特定扫描速率下的赝电容贡献率.

从图 $5(\mathrm{~g})$ 的统计结果可知, 扫描速率为 $0.1 、 0.2$ 、 0.4、0.6、0.8 和 $1.0 \mathrm{mV} / \mathrm{s}$ 时所对应的噟电容贡献率分别 为 $54.1 \% 、 58.6 \% 、 72 \% 、 71.1 \% 、 75.3 \%$ 和 $78.8 \%$, 而电 池贡献率分别是 $45.9 \% 、 41.4 \% 、 28 \% 、 28.9 \% 、 24.7 \%$ 和 $21.2 \%$, 这一结果进一步证实了本工作所制备的样品 同时包含了电池属性和赝电容属性，二者共同储存了电 荷. 并且从图 $5(\mathrm{~g})$ 可以进一步得出, 所制备的 $\mathrm{Cu}_{3} \mathrm{Si}$ 样 品的噟电容贡献率高于电池, 并且扫描速率越高噟电容 贡献率越大. 扫描加快导致 “电容贡献比例” 变大, 其 主要原因是 $\mathrm{Li}^{+}$的表面扩散速率远大于其在 $\mathrm{Cu}_{3} \mathrm{Si}$ 体相 内的扩散速率, 因此, 当扫描速率加快后, $\mathrm{Cu}_{3} \mathrm{Si}$ 体相内 的氧化还原速率急剧下降, 从而表现为整体上电容贡献

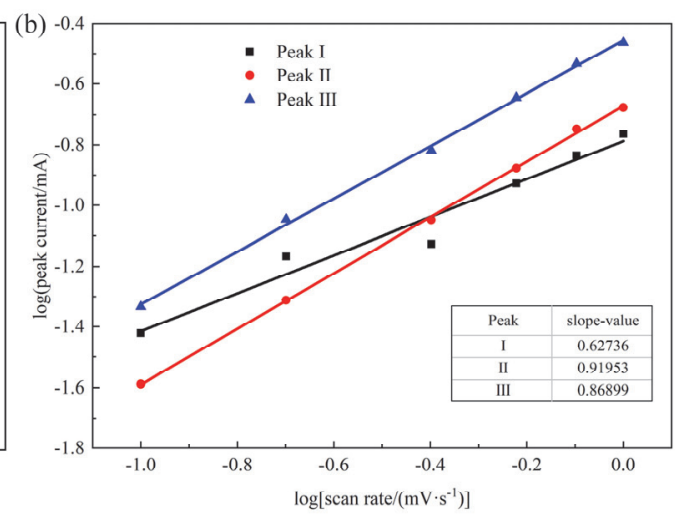

图 4 (a)不同扫描速率的 CV 图; (b)峰值电流与扫描速率的对数图

Figure 4 (a) CVs at different scan rate; (b) logarithmic curves of peak current and scanning rate 

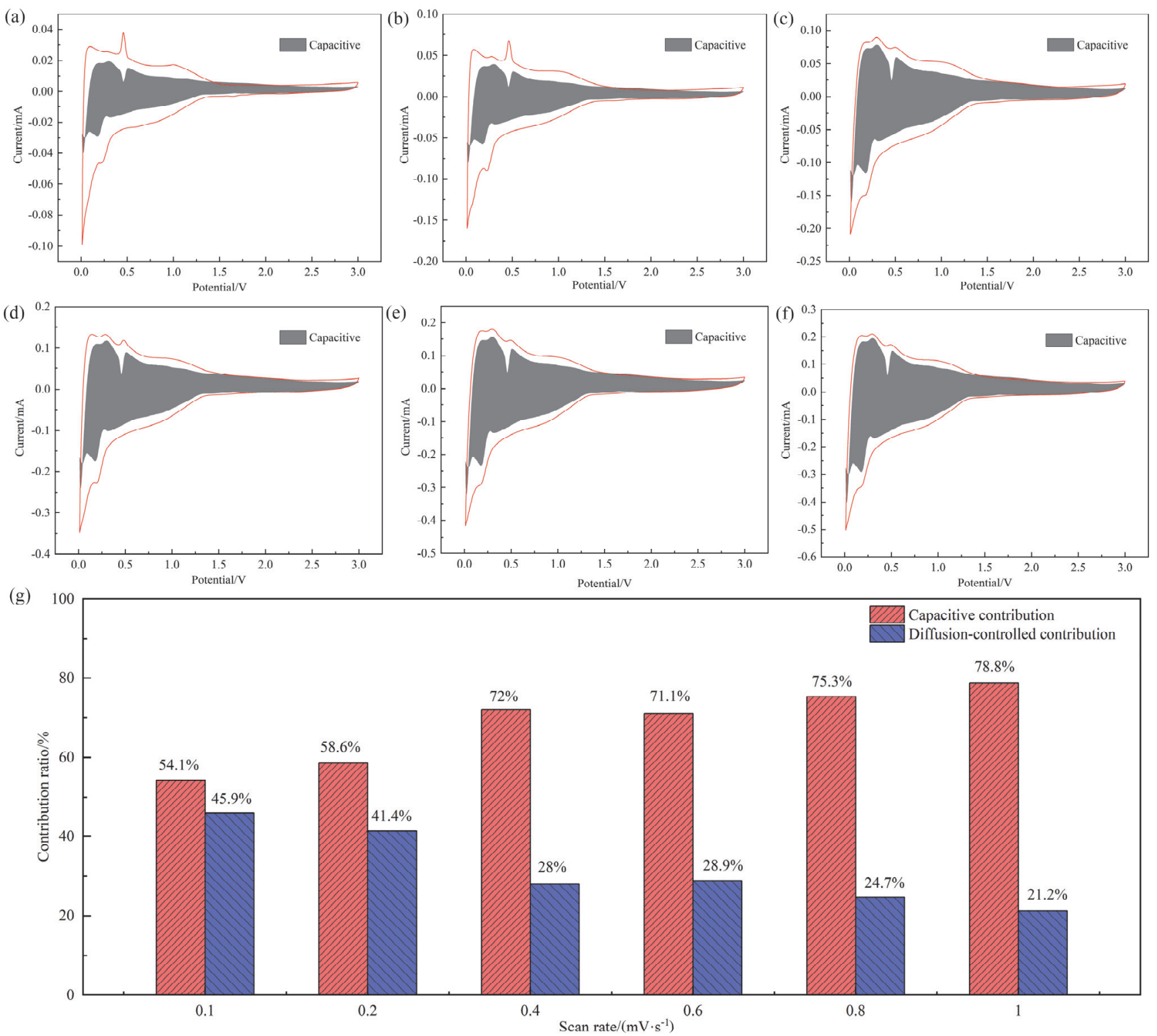

图 5 (a) 0.1 , (b) 0.2, (c) 0.4, (d) 0.6, (e) 0.8 和(f) $1.0 \mathrm{mV} / \mathrm{s}$ 扫描速率下的赝电容贡献; (g)电荷储存贡献比

Figure 5 The pseudocapacitive contribution at the scan rate of (a) 0.1 , (b) 0.2 , (c) 0.4 , (d) 0.6 , (e) 0.8 and (f) $1.0 \mathrm{mV} / \mathrm{s}$; (g) the percentage of charge storage contribution

率增大的现象.

另一方面，由于所制备的样品中 $\mathrm{Si}$ 的含量小于 $1 \%$, 说明图 5(g)中超过 $20 \%$ 的贡献率不可能来自 $\mathrm{Si}$ 对样品 的电池行为贡献. 由此可得出, $\mathrm{Cu}_{3} \mathrm{Si}$ 是一种典型的赝电 容材料, 且同时含有电池行为.

虽然 $\mathrm{Cu}_{3} \mathrm{Si}$ 是一种同时包含赝电容和电池属性的材 料, 但从图 3(a)的充放电曲线来看, 并没有观测到明显 的充放平台，查阅文献可知，硅和石墨等负极在嵌锂过 程属于一级相变过程 ${ }^{[39-40]}$, 其氧化还原过程如下:

$$
\begin{aligned}
& x \mathrm{Li}^{+}+x e^{-}+\mathrm{C}_{6} \rightarrow \mathrm{Li}_{x} \mathrm{C}_{6} \\
& x \mathrm{Li}^{+}+x e^{-}+\mathrm{Si} \rightarrow \mathrm{Li}_{x} \mathrm{Si}
\end{aligned}
$$

方程式(4)和(5)中, $\mathrm{Li}^{+}$电荷转移: $\mathrm{Li}^{+}$到达负极并在 负极 SEI 界面或负极集流体/SEI 界面接受电子, 而电子 则是充电过程中通过外部电路提供. 因此, 不管是石墨 还是硅负极，其两相反应电位曲线一般出现显著的平台 区域, 反映的相变为一级相变, 在嵌锂的过程中均伴随 着明显的一级相变特征, 即会发生显著的体积膨胀. 而 从图 3(a)的充放电曲线可以预知, $\mathrm{Cu}_{3} \mathrm{Si}$ 的嵌锂过程不是 一级相变反应.

为了进一步证明, 本工作以 $0.1 \mathrm{C}$ 的充放电倍率, 经 过 10 圈的充放电循环后, 将完成第 11 圈充电和第 11 圈 放电的两个扣式电池进行拆解, 并取出其中的负极极片 进行 XRD 分析, 然后将极片上的样品刮下后进行吸放 热(DSC)曲线检测, 结果如图 6 所示. 

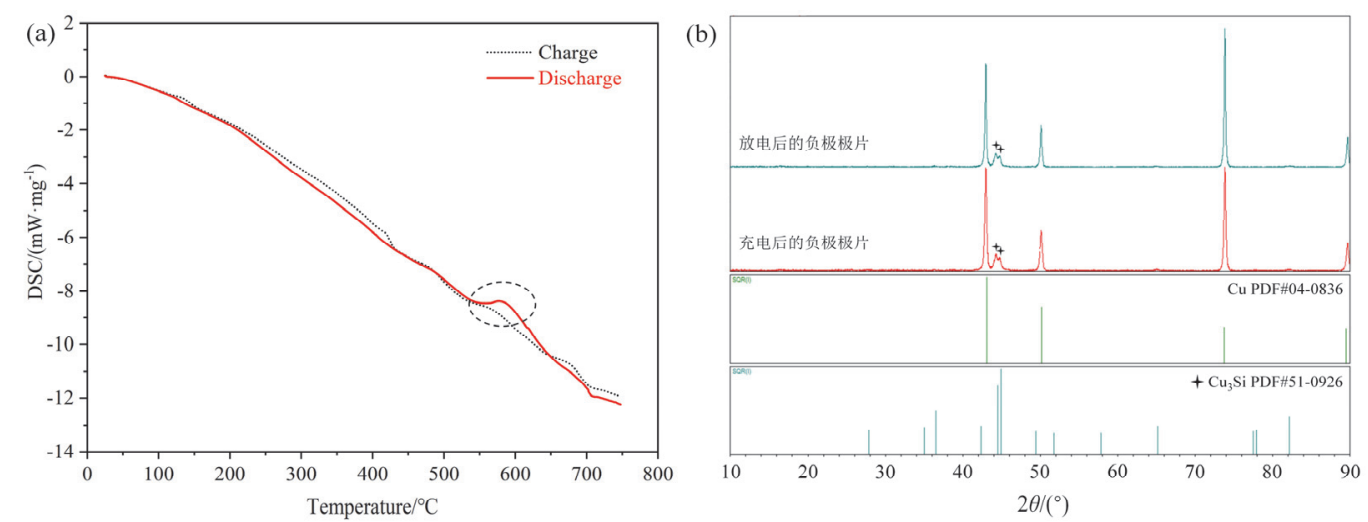

图 6 分别对第 11 圈充电后和第 11 圈放电后的两个扣式电池负极的表征: (a)负极样品的 DSC 曲线, (b)负极极片的 XRD 图谱分析 Figure 6 Characterization of the anode of the two coin-cells after their 11th cycle of charge and discharge, respectively: (a) DSC curves, (b) XRD analysis

从图 6(a)的 DSC 曲线可以看出, 充电后和放电后的 样品 DSC 曲线基本重合, 但放电后的样品 DSC 曲线在 温度为 $550 \sim 600{ }^{\circ} \mathrm{C}$ 可以观测到一个明显台阶, 说明在 该温度范围内伴随着样品比热容的变化. 而从图 6(b)的 负极极片 XRD 图谱可以看出, 充电后和放电后的样品 始终保持 $\mathrm{Cu}_{3} \mathrm{Si}$ 相, 并没有新的物相产生. 由于扣式半 电池的放电过程对应于 $\mathrm{Li}^{+}$嵌入 $\mathrm{Cu}_{3} \mathrm{Si}$ 的过程, 因此, 可 以推断, 在放电后的样品进行升温时, 当温度高于 $550{ }^{\circ} \mathrm{C}$ 时发生了如下反应过程:

$$
\mathrm{Cu}_{3} \mathrm{Si}: x \mathrm{Li} \rightarrow \mathrm{Cu}_{3} \mathrm{Si}+x \mathrm{Li}
$$

从反应式(6)可以看出, 高温下锂从 $\mathrm{Cu}_{3} \mathrm{Si}$ 相中固溶 脱出, 并不会影响 $\mathrm{Cu}_{3} \mathrm{Si}$ 的物相结构, 这一点可以从图 6(a)并没有明显的放热或吸热峰来证实. 因此, 结合图 6(b) 可以确认, $\mathrm{Cu}_{3} \mathrm{Si}$ 的脱嵌锂过程并未发生一级相变, $\mathrm{Li}^{+}$的嵌入和脱出可以理解为一个固溶反应过程, 其充 放电的氧化还原过程可表示为式(7):

$$
x \mathrm{Li}^{+}+x e^{-}+\mathrm{Cu}_{3} \mathrm{Si} \rightarrow \mathrm{Cu}_{3} \mathrm{Si}: x \mathrm{Li}
$$

因此, 充放电过程中结构保持固溶体形式的相变反 应, 其 DSC 曲线具有明显的台阶特征, 表现为充放电过 程比热容的变化, 证明 $\mathrm{Cu}_{3} \mathrm{Si}$ 的脱嵌锂过程属于二级相 变过程, 而二级相变过程的充放电曲线为斜坡状 ${ }^{[41]}$, 这 与图 3(a)的结果不谋而合.

因此, 就 $\mathrm{Cu}_{3} \mathrm{Si}$ 材料而言, 它同时包含噟电容和电 池属性, 且其电池属性属于二级相变, 两种属性反映在 充放电曲线均为斜坡状. 所以, 有充分的理由相信, 二 级相变材料所表现出的电化学行为即为一种赝电容行 为.

\section{3 结论}

本工作采用冶金法制备了纯度较高的 $\mathrm{Cu}_{3} \mathrm{Si}$ 相, 并 对其电化学性能进行了表征, 结果表明, 在 $0.1 \mathrm{C}$ 的充放
电倍率下所制备的样品表现出非常稳定的充放电性能. 首次放电比容量 $759 \mathrm{mAh} \cdot \mathrm{g}^{-1}$, 首次库伦效率 $96.56 \%$. 样品的最高放电比容量为 $837 \mathrm{mAh} \cdot \mathrm{g}^{-1}$, 循环 200 次之 后放电比容量是 $822 \mathrm{mAh} \cdot \mathrm{g}^{-1}$, 容量保持率达到 $98 \%$. 在倍率为 $0.1 \mathrm{C} 、 0.2 \mathrm{C} 、 0.4 \mathrm{C} 、 0.6 \mathrm{C} 、 0.8 \mathrm{C}$ 和 $1 \mathrm{C}$ 时, 比容 量分别达到 776、700、580、500、440 和 $405 \mathrm{mAh} \cdot \mathrm{g}^{-1}$. 当 倍率回到 $0.1 \mathrm{C}$ 时, 比容量回到 $790 \mathrm{mAh} \cdot \mathrm{g}^{-1}$, 与初始值 比较, 并未发生明显的降低. 样品的交流阻抗值约为 60 $\Omega$, 明显小于已报道的 $\mathrm{Si} @ \mathrm{C}$ 负极, 说明 $\mathrm{Cu}$ 的加入极大 降低了负极材料的电荷转移阻力.

本工作分别采用扫描速率为 $0.1 、 0.2 、 0.4 、 0.6 、 0.8$ 和 $1.0 \mathrm{mV} / \mathrm{s}$ 对所制备的样品进行 CV 测试, 结果表明所 制备的样品的电化学特性既有电池属性, 又包含电容属 性成分, 二者共同储存了电荷. 而且放电后的样品 DSC 曲线在温度为 $550 \sim 600{ }^{\circ} \mathrm{C}$ 可以观测到一个明显台阶, 说明在该温度范围内伴随着样品比热容的变化. 因此, $\mathrm{Cu}_{3} \mathrm{Si}$ 的脱嵌锂过程并未发生一级相变, $\mathrm{Li}^{+}$的嵌入和脱 出可以理解为一个固溶反应过程, 故 $\mathrm{Cu}_{3} \mathrm{Si}$ 的脱嵌锂过 程属于二级相变过程，且其充放电曲线为斜坡状. 所以， 有充分的理由相信, 二级相变材料所表现出的电化学行 为即为一种赝电容行为.

\section{4 实验部分}

\section{1 材料制备}

本实验采用 DLZ-15 型高频感应熔炼炉 (如图 7(a)所 示, 上海子林), 在感应熔炼炉中放入石墨坩埚, 图 7(b) 所示的石墨坩埚尺寸为外径 $85 \mathrm{~mm}$, 内径 $70 \mathrm{~mm}$, 外高 $110 \mathrm{~mm}$, 石墨坩埚加盖.

首先把 $30 \mathrm{~g}$ 硅原料加入石墨坩埚中并盖上盖子，按 $0.2 \mathrm{~kW} / \mathrm{min}$ 增加感应功率到 $7 \mathrm{~kW}$ 后保持 $10 \mathrm{~min}$. 打开 盖子, 采用 TM990D 型红外测温枪测量温度, 炉体温度

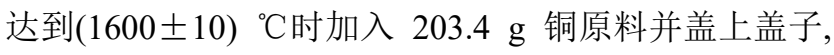
$10 \mathrm{~min}$ 后把熔融液体倒入常温杯状石墨模具(如图 7(c) 所示)中, 并在空气中冷却至室温得到 $\mathrm{Cu}_{3} \mathrm{Si}$ 样品. 


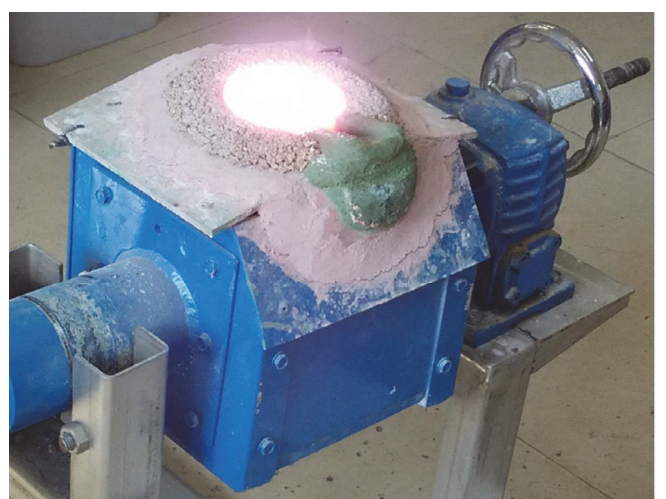

(a)

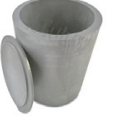

(b)

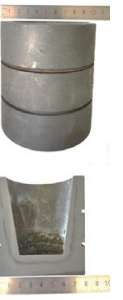

(c)

图 7 (a) DLZ-15 型高频感应熔炼炉, (b)石墨坩埚, (c)石墨模具

Figure 7 (a) DLZ-15 high frequency induction melting furnace, (b) graphite crucible, (c) graphite mold

\section{2 电池组装与电化学测试}

采用 F-P2000 型行星式球磨机粉碎样品, 转速 480 $\mathrm{r} / \mathrm{min}$, 时间 $24 \mathrm{~h}$. 称量 $0.3 \mathrm{~g}$ 样品粉末、 $0.1 \mathrm{~g}$ 粘结剂海 藻酸钠、 $0.1 \mathrm{~g}$ 导电碳黑, 加入 $5 \mathrm{~mL}$ 去离子水, 磁力摚 拌 $6 \mathrm{~h}$. 把浆料均匀涂抹在铜箔上, 涂抹厚度 $100 \mu \mathrm{m}$, 空气中放置 $12 \mathrm{~h}$, 随后于 $70{ }^{\circ} \mathrm{C}$ 真空干燥箱中干燥 $24 \mathrm{~h}$, 用冲片机裁剪 $12 \mathrm{~mm}$ 圆片作为工作电极. 以工作电极为 正极, Celgard 2500 膜为隔膜, 金属锂为参比电极, 加入 $60 \mu \mathrm{m}$ LB-291 型锂离子电池电解液, 在氩气手套箱中组 装 CR2025 型纽扣半电池.

采用 CT2001A 型电池测试系统对电池进行恒流充 放电测试, 测试倍率 $0.1 \mathrm{C}\left(420 \mathrm{~mA} \cdot \mathrm{g}^{-1}\right)$, 电压范围 $0.01 \sim 1.2 \mathrm{~V}$, 测试温度 $30{ }^{\circ} \mathrm{C}$. 采用 CHI660E 型电化学 工作站进行循环伏安测试 (CV) 和电化学交流阻抗测试 (EIS), CV 测试电压范围 0.01 3 V, EIS 频率范围 1 $100000 \mathrm{~Hz}$.

\section{3 物理表征}

采用 Rigaku Ultima IV 型 X 射线衍射仪进行物相测 试, 测试条件: 工作电流 $30 \mathrm{~mA}$, 工作电压 $40 \mathrm{kV}$, 以 $\mathrm{Cu}$ $\mathrm{K} \alpha$ 为辐射源, 测试角度 $10^{\circ} \sim 90^{\circ}$, 扫描速度 $10\left(^{\circ}\right) / \mathrm{min}$. 采用 UNPOL-1210 型金相磨抛机打磨样品坚切面, 采用 F-P2000 型高能球磨机粉碎样品. 采用 SUPRA55 SAPPHIRE 型场发射扫描电子显微镜观察样品截面, 该 仪器配备能谱仪. 采用 STA449F5 型同步热分析仪进行 DSC 测试, 测试条件: 氩气流量 $40 \mathrm{~mL} / \mathrm{min}$, 加热温度 $750{ }^{\circ} \mathrm{C}$, 加热速率 $10{ }^{\circ} \mathrm{C} / \mathrm{min}$.

\section{References}

[1] Miao, P.; Yao, Z.; Lemmon, J.; Liu, Q.-H.; Wang, B.-G. Energy Storage Sci. Technol. 2020, 9, 670 (in Chinese). (缪平, 姚祯, Lemmon John, 刘庆华, 王保国, 储能科学技术, 2020, 9, 670.)

[2] Nitta, N.; Wu, F.; Lee, J. T.; Yushin, G. Mater. Today 2015, 18, 252.

[3] Etacheri, V.; Marom, R.; Elazari, R.; Salitra, G.; Aurbach, D. Energy Environ. Sci. 2011, 4, 3243.

[4] Etacheri, V.; Haik, O.; Goffer, Y.; Roberts, G. A.; Stefan, I. C.; Fasching, R.; Aurbach, D. Langmuir 2012, 28, 965.

[5] Ge, M.; Rong, J.; Fang, X.; Zhou, C. Nano Lett. 2012, 12, 2318.

[6] Cui, L.-F.; Hu, L.; Choi, J.-W.; Cui, Y. ACS Nano 2010, 4, 3671.

[7] Wu, H.; Zheng, G.; Liu, N.; Carney, T. J.; Yang, Y.; Cui, Y. Nano Lett. 2012, 12, 904.

[8] Yoo, E.; Kim, J.; Hosono, E.; Zhou, H.-S.; Kudo, T.; Honma, I. Nano Lett. 2008, 8, 2277.

[9] Li, Y.-M.; Hao, G.-D.; Cui, P.; Yi, Y.-F. Chem. Ind. Eng. 2020, 37, 17 (in Chinese). (李艳梅, 郝国栋, 崔平, 伊廷锋, 化学工业与工程, 2020, 37, 17.)

[10] Sharma, P.; Bhatti, T. S. Energy Convers. Manage. 2010, 51, 2901.

[11] Liang, X.-T.; Pan, W.; Chen, K.-F.; Xue, D.-F. Chin. J. Appl. Chem. 2016, 33, 867 (in Chinese). (梁晰童, 潘伟, 陈昆峰, 薛冬峰, 应用 化学, 2016, 33, 867.)

[12] Fan, Z.-J. Acta Physico-Chimica Sinica 2020, 36, 1907018 (in Chinese). (范壮军, 物理化学学报, 2020, 36, 1907018.)

[13] Najib, S.; Erdem, E. Nanoscale Adv. 2019, 1, 2817.

[14] Wang, F.; Cheong, J. Y.; Lee, J.; Ahn, J.; Duan, G.; Chen, H.; Qian, Z.; Kim, I; Jiang, S. Adv. Funct. Mater. 2021, 2101077.

[15] Frackowiak, E. Phys. Chem. Chem. 2007, 9, 1774.

[16] Zhang, L.-L.; Zhao, X.-S. Chem. Soc. Rev. 2009, 38, 2520.

[17] Naoi, K.; Naoi, W.; Aoyagi, S.; Miyamoto, J. I.; Kamino, T. Acc. Chem. Res. 2013, 46, 1075.

[18] Yu, Z.; Tetard, L.; Zhai, L.; Thomas, J. Energy Environ. Sci. 2015, 8, 702.

[19] Najib, S.; Erdem, E. Nanoscale Adv. 2019, 1, 2817.

[20] Jiang, Y.; Liu, J. Energy Environ. Sci. 2019, 2, 30.

[21] Okubo, M.; Hosono, E.; Kim, J.; Enomoto, M.; Kojima, N.; Kudo, T.; Zhou, H.; Honma, I. J. Am. Chem. Soc. 2007, 129, 7444.

[22] Gogotsi, Y.; Penner, R. M. ACS Nano 2018, 12, 2081.

[23] Simon, P.; Gogotsi, Y.; Dunn, B. Science 2014, 343, 1210.

[24] Qi, P.; Chen, A.-Y. Chin. J. Power Sources 2020, 44, 1235 (in Chinese). (祁鹏，陈爱英，电源技术, 2020, 44, 1235.)

[25] Augustyn, V.; Simon, P.; Dunn, B. Energy Environ. Sci. 2014, 7, 1597.

[26] Dodony, E.; Radnóczi, G. Z.; Dódony, I. Intermetallics 2019, 107, 108.

[27] Gupta, R.; Kumar, R.; Chauhan, R. P.; Chakarvarti, S. K. Vacuum 2018, 148, 239.

[28] Többens, D. M.; Stüßer, N.; Knorr, K.; Mayer, H. M.; Lampert, G. Mater. Sci. Forum. 2001, 378-381, 288.

[29] Fan, Z.-Q.; Zheng, S.-S.; He, S.; Ye, Y.-Y.; Liang, J.-H.; Shi, A.-D.; Wang, Z.-L.; Zheng, Z.-F. Diamond Relat. Mater. 2020, 107, 107898.

[30] Fan, Z.-Q.; Wang, Y.-T.; Zheng, S.-S.; Xu, K.; Wu, J.-Y.; Chen, S.; Liang, J.-H.; Shi, A.-D.; Wang, Z.-L. Energy Storage Mater. 2021, $39,1$.

[31] Liang, J.-H.; Fan, Z.-Q.; Chen, S.; Zheng, S.-S.; Wang, Z.-L. J. Alloys Compd. 2021, 860, 158433.

[32] Fu, Q.; Liu, S.-Q.; Sarapulova, A.; Zhu, L.-H.; Etter, M.; Welter, E.; Weidler, P. G.; Knapp, M.; Ehrenberg, H.; Dsoke, S. Adv. Energy Mater. 2019, 9, 1901864.

[33] Lu, Y.-Y.; Wang, Z.-Y. Higher Education in Chemical Engineering 2021, 38, 73 (in Chinese). (陆盈盈, 王卓雅, 化工高等教育, 2021, 38,73 .)

[34] Lindström, H.; Södergren, S.; Solbrand, A.; Rensmo, H.; Hjelm, J.; Hagfeldt, A.; Lindquist, S. E. J. Phys. Chem. B 1997, 101, 2598.

[35] Bard, A. J.; Faulkner, L. R. Electrochem. Methods 2001, 2, 482.

[36] Augustyn, V.; Come, J.; Lowe, M. A.; Kim, J. W.; Taberna, P. L.; Tolbert, S. H.; Abruña H. D.; Simon, P.; Dunn, B. Nat. Mater. 2013, 12,518 .

[37] Liu, T. C.; Pell, W. G.; Conway, B. E.; Roberson, S. L. J. Electrochem. Soc. 1998, 145, 1882.

[38] Wang, J.; Polleux, J.; Lim, J.; Dunn, B. J. Phys. Chem. C 2007, 111, 14925 .

[39] McDowell, M. T.; Lee, S. W.; Nix, W. D.; Cui, Y. Adv. Mater. 2013, 25,4966 .

[40] Jow, T. R.; Delp, S. A.; Allen, J. L.; Jones, J. P. J. Electrochem. Soc. 2018, 165, A361.

[41] Gao, J.; Lü, Y.-C.; Li, H. Energy Storage Sci. Technol. 2013, 2, 250 (in Chinese). (高健，吕迎春，李泓，储能科学与技术，2013，2， 250.) 